\title{
The Efficiency of the Art Market: Evidence from Variance Ratio Tests, Linear and Nonlinear Fractional Integration Approaches ${ }^{\#}$

\author{
Goodness C. Aye , Luis A. Gil-Alana ${ }^{* *}$, Rangan Gupta ${ }^{* * *}$ and Mark E. Wohar ${ }^{* * *}$
}

\begin{abstract}
This paper investigates the weak-form efficiency hypothesis for the art market. We consider 15 art price indices namely: Contemporary, Drawings, France, Global index (Euro), Global index (USD), Modern art, Nineteenth century, Old Masters, Paintings, Photographies, Postwar, Prints, Sculptures, UK and US. We use quarterly data from 1998:1 to 2015: 1. We employ both standard and nonparametric single and joint variance ratio tests while accounting for small sample bias through the use of the wild bootstrapping. We show that the majority of the art markets are inefficient with the exception of the Old Masters that consistently prove efficient under both individual and joint variance ratio tests. To a lesser extent Contemporary, US and UK markets are also efficient. However, confronting the data with both linear and nonlinear long memory models as robustness check, we observe that Paints, Prints, Photographies, Nineteenth century, Modern Art, US, France and Drawings have unit roots and are therefore efficient. Others such as Post war Sculpture, and Contemporary have values of the fractional parameter $d$ significantly different from 0 and 1 and they may be considered efficient as well in a number of cases. The US and Contemporary art markets appear to be efficient irrespective of the method used.
\end{abstract}

Keywords: Art market, market efficiency, variance ratio tests, random walk, martingale, nonparametric

JEL Classification: C14, G14, G15

\footnotetext{
\# We would like to thank the Editor, Professor Carl Chen, and two anonymous referees for many helpful comments. However, any remaining errors are solely ours.

* Department of Economics, University of Pretoria, Pretoria, 0002, South Africa. Email: goodness.aye@gmail.com.

** University of Navarra, Faculty of Economics and ICS (NCID), Edificio Amigos, E-31080 Pamplona, Spain. Email: alana@unav.es. This author gratefully acknowledges financial support from the Ministerio de Economía y Competitividad (SEJ2014-2017, ECO2014-55236).

*** Department of Economics, University of Pretoria, Pretoria, 0002, South Africa. Email: rangan.gupta@up.ac.za.

**** Corresponding author. College of Business Administration, University of Nebraska at Omaha, 6708 Pine Street, Omaha, NE 68182, USA, and School of Business and Economics, Loughborough University, Leicestershire, LE11 3TU, UK. Email: mwohar@,unomaha.edu.
} 


\section{Introduction}

Investors often seek alternative assets and sophisticated solutions to acquire high returns while minimizing risk, especially when faced with under-performing portfolios. This has become more important since the aftermath of the recent financial crisis with a serious weakening in the value of most financial assets. The average annual returns from art have been as high as $10 \%$ for a very long period (Munteanu and Pece, 2015). Campbell (2008) also examines the financial gains that artworks have exhibited historically while including transaction costs, and show that arts offer diversification benefits as an investment portfolio given its low correlation with other asset classes. Also optimal portfolio allocations using historical returns make a case for investors to consider art as an attractive, albeit small addition to their investment strategy. Louargand and McDaniel (1991), Ashenfelter and Graddy (2003), after examining the auction market, argue that the increase in liquidity, better information in art auction catalogues, globalization, access to financing options, and the increase of participation in the auction markets are among the reasons that the art market has become more efficient. This suggests that art prices should be unpredictable or random (Louargand and McDaniel 1991). Further estimates based on hedonic price index of oil paintings, watercolors and drawings by Renneboog and Spaenjers (2013) show that between 1982 and 2007, art prices rose 3.97\% annually thus outperforming returns from physical and financial assets: commodities (3.3\%), gold (2.35\%), US real estate $(1.06 \%)$ and T-Bills $(1.39 \%)$. This view is challenged recently by Korteweg et al. (2016) who argue that investors tend to overestimate the returns and underestimate the risks involved in selling and buying art work. Korteweg et al. (2016) show that average annual return for art investment decline from $10 \%$ to $6.2 \%$ making it less appealing than stock $(10.95 \%)$, corporate bonds (8.94\%) and commodities (10.21\%).

Although there are many studies on different aspects of the art market, there is a dearth of studies on art market efficiency as is evidenced in the literature section below. Under the weak-form efficiency, the returns are purely unpredictable and no investors are able to make abnormal profit consistently over time by exploiting past price information (Fama, 1970). However, if the art market is not efficient, as a result of price formation which is opaque to outsiders who lack information on unsold artworks, then investors can easily capitalize on this to make excess profits. Therefore, the understanding of the efficiency or otherwise of the art market may be useful to investors in their portfolio diversification decisions and risk management. Market efficiency gives investors 
confidence in the fairness of market valuation. Some developments in the art market may support its efficiency namely increase in liquidity, better information in art auction catalogues, globalization, access to financing options, and the increase of participation in the auction markets are among others thus suggesting that art prices should be unpredictable or random (Louargand and McDaniel 1991). This argument has however been countered by some researchers. For instance, David et al. (2013) argued that it is structurally impossible for auction prices to be efficient. This is because sellers set a minimum transaction price on the artworks for which they have a monopoly and hammer prices are determined solely by bidding, so that there is no upper limit. Consequently, relying on realized prices is insufficient to build unbiased predictions of future prices. Empirically, as will be seen in the literature review part, the conclusions are also mixed.

In this study we contribute by investigating the art market efficiency (i.e. return predictability) for the recent period 1998 to 2015 using data from Artprice.com. We consider conventional and nonparametric variance ratio tests for both individual and multiple tests namely Lo and Mackinlay (1988), Wright's (2000) ranks and signs tests, Chow and Dennings (1993) and Belaire-Franch and Contreras (2004) joint tests. Our choice of variance ratio tests instead of the unit root tests as in Çevik et al. (2013) and related papers is motivated by the fact that the former is a volatility-based test. This feature is important given that most asset returns often exhibit volatility and deviations from normality (Belaire-Franch et al., 2007). Hence tests such as the variance ratio tests which are robust to heteroskedasticity and non-normality become important. Earlier, Poterba and Summers (1988) investigate the power of different random walk tests and find that variance ratios are among the most powerful tests and it has even more power than the Fama and French (1988) regression based procedure. In addition, studies like that of Summers (1986), Poterba and Summers (1988), Cochrane (1988), Fama and French (1988), Lo and MacKinlay (1988), Liu and He (1991), Erdös and Ormos (2010) and Mobarek and Fiorante (2014) have argued that unit root tests have very low power against stationary alternatives and it is difficult to reject a false null hypothesis of random walk. ${ }^{1}$ Note that from the perspective of data, our paper is closest to that of Çevik et al. (2013), as we use the same set of indices, but an updated period until 2015 and employ variance ratio tests

\footnotetext{
1 Unit root tests most commonly employed in the literature (Dickey and Fuller, 1979; Phillips and Perron, 1988; Kwiatkowski et al., 1992; etc.) have very low power against trend-stationarity (DeJong, et al., 1992), structural breaks (Perron, 1989; Campbell and Perron, 1991), regime-switching (Nelson, et al., 2001), or fractional integration (Diebold and Rudebusch, 1991; Hassler and Wolters, 1994; Lee and Schmidt, 1996).
} 
rather than unit root tests. However, unlike a recent and closely related study on art market efficiency by Munteanu and Pece (2015) who, using our approach of the variance ratio tests, focused on four major auction houses - Sotheby's, Turners Auctions Ltd, Mallett PLC and Mowbray Collectables- we, as in Çevik et al. (2013), study a wider set of art indices including Contemporary, Drawings, France, Global (Euro), Global (USD), Modern art, Nineteenth century, Old Masters, Paintings, Photographies, Postwar, Prints, Sculptures, UK and US indices. Finally, for the conventional variance ratio tests which ordinarily use asymptotic normal probabilities to evaluate statistical significance, we use Kim's (2006) wild bootstrap p-values to guard against small sample bias.

As a robustness check, we also analyze the efficiency of the art market using fractional techniques based on long memory models Though the fractional integration models are new in the art market efficiency analysis, they have been used successfully in other academic research (Gil-Alana, 2008; Arouri et al., 2012; Gil-Alana and Moreno, 2012; Gil-Alana et al., 2015). These models are able to account for long memory behavior and nonlinearities evidenced in most financial and economic time series. The fractional integration framework allows us to simultaneously and endogenously determine the order of integration of the art market indices without restricting us to choose a priori between zero and one. It is flexible and simply lets the data speak. The order of integration could be zero, a fraction of one, or it could even be above one. Therefore, the approach is agnostic with respect to the order of integration of the art market indices. The fractional integration approach achieves the goal of establishing the existence or otherwise of a random behaviour or return independence with much more flexibility than most standard unit root test techniques.

The remainder of the paper is organized as follows: Section 2 reviews the literature, while section 3 discusses the data. The empirical models used are presented in section 4 . Section 5 presents the results, and section 6 concludes. 


\section{Literature Review}

Many time series variables exhibit trend behavior and they are relevant to the study of market efficiency. According to Fama (1970), to be efficient, an asset should follow a random walk. In this case, the direction and prices of art should not be predictable. Investors must not profit from information already available. A market is said to be efficient if prices fully reflect all available information. According to Fama (1970), there exists three forms of market efficiency. When only historical price information is available to investors, then we have weak form efficiency. When prices incorporate all publicly available information, then we have semi-strong form efficiency. The semistrong form also incorporates the weak form efficiency. The strong form efficiency exists when all public and private information are factored into the current prices (David et al., 2013). Both weak form and semi-strong form efficiency are incorporated in the strong form efficiency. Market efficiency reflects the fairness of market value and hence is very important for investors.

One problem with doing reliable efficiency analysis is difficulties associated with computing relevant series of art returns. Due to limited data availability, it was thought that testing for market efficiency is very difficult (Frey and Eichenberger ,1995). However, some studies have attempted to examine this. For instance, David, et al. (2013) use the hedonic art index developed by Renneboog and Spaenjers (2013). They propose tests for weak efficiency of the art market based on time-series analysis with annual data from 1957-2007. Results based on Ljung-Box test show that art returns exhibit highly auto-regressive dynamics. Also the variance ratio tests rejects random walk hypothesis while the run and Bartels tests reject return independence. These findings imply that weak efficiency is rejected.

Erdös and Ormos (2010) conduct variance ratio tests based on non-parametric methods to detect the size of the random walk component of the US art auction prices. Their annual data comprise of a combination of the Mei and Moses' (2002) art index and the US subindex of the Artprice Global Index family from 1875 to 2008. They find that the past 134 years of US art prices exhibit large transitory component $(72 \%)$ and consequently, the random walk hypothesis does not hold. They detect structural breakpoints and find that the random walk hypothesis and the weak-form efficiency of US art market cannot be rejected at least for the past 64 years. Applying the Cochrane (1988) variance ratio estimation, they find that the random walk hypothesis can be rejected for the whole 
sample period. However, if they exclude the first 60 years from the sample, the random walk hypothesis cannot be rejected.

Çevik et al. (2013) examine the time series properties of art price indices in the global art market and in its various segments. They used quarterly data from covering the period 1990-2011 and Markov regime-switching ADF model. Their results indicate that the overall global art market (in USD) is found to be a stationary process at $1 \%$ level. The price indices for the Sculptures, Photographs, Old Masters, Contemporary, Paintings and Prints are stationary, hence providing evidence of meanreversion. The price indices for Drawings and Nineteenth century were found to be non-stationary and hence according to the authors are in some sense closest to exhibiting at least weak-form efficiency.

Munteanu and Pece (2015) investigate the returns obtained by auction houses using daily data from April 2005-March 2014. They test the market efficiency of the most influential auction house as a signal for art market robustness. They focus on how investors use information regarding the activity of four major auction houses - Sotheby's, Turners Auctions Ltd, Mallett PLC and Mowbray Collectables - and how this information is reflected in the price of the art indices. They conduct several tests of market efficiency (in particular, Automatic Variance Ratio test, Joint Wright test, and the Lo and MacKinlay test). The results indicate that while some indices exhibit market efficiency, others present a slow assimilation of information and hence past information can be used to make predictions.

Frey and Pommerehne (1989) find that real art returns do not follow a normal distribution and conclude that prices seem not to follow a pure random process employing annual data for the period 1635-1949. This is contrary to the results of Baumol's (1986) who also used annual data for the period 1652-1961. Poterba and Summer (1988) show that the random walk tests have low power if only a short span of data is available. Pesando (1993) investigates the prints market using semiannual price index over the 1977-1992 period and finds that excess returns are autocorrelated positively for the one-year lag and negatively for the two-year lag.

With respect to the contribution of our paper, our work is closest to that of Çevik et al. (2013) who conduct unit root tests on the level of art indices. We use the same set of indices, but we use an 
updated period until 2015 and employ variance ratio tests rather than unit root tests. Munteanu and Pece (2015) employ art return series on four major auction houses - Sotheby's, Turners Auctions Ltd, Mallett PLC and Mowbray Collectables- and employ variance ratio tests. We study a much wider set of art indices. Furthermore, for the conventional variance ratio tests which ordinarily use asymptotic normal probabilities to evaluate statistical significance, we use Kim (2006) wild bootstrap p-values to guard against small sample bias. However as a robustness check, we also analyze the efficiency of the art market using fractional techniques. These models are able to account for long memory behavior (Gil-Alana, 2008; Cuestas and Gil-Alana, 2016) and nonlinearities (Diebold and Inoue, 2001; Kapetanious and Shin, 2011; Cuestas and Gil-Alana, 2016) evidenced in most financial and economic time series. By allowing for fractional degrees of differentiation we allow for a higher degree of flexibility in the dynamic specification of the data, including as particular cases of interest the stationary $\mathrm{I}(0)$ and the nonstationary $\mathrm{I}(1)$ cases.

\section{Data}

This study uses quarterly data spanning 1998:1 to 2015:1 on 15 art market price indices returns namely Contemporary, Drawings, France, Global index (Euro), Global index (USD), Modern art, Nineteenth century, Old Masters, Paintings, Photographies, Postwar, Prints, Sculptures, UK and US indices. The data is obtained from Artprice, available for download from: http://www.artprice.com. The art market price indices are calculated by the Artprice ${ }^{\mathrm{TM}}$, a company specializing in art market information and data services. Over 405,000 artists are included in the database. A repeat-sales model drawn from a database of over 27 million auction records from over 3,600 auction houses around the world were used in calculating the indices. A repeat sales takes place if two works of art are sold sequentially which are by the same artist and their size, technique, materials, medium and the date of creation are matched. The infrequent sales and uniqueness of each item sold among others makes the calculation of the overall price indices from Artprice difficult. However, the data from Artprice is similar to other existing indices like the one developed by Mei and Moses (2002) since major art market indices follow a similar trend and capture the mood of the art market developments (Erdös and Ormos, 2010; Çevik et al., 2013). The availability of comprehensive dataset and at quarterly frequency makes the data base maintained by Artprice ${ }^{\mathrm{TM}}$ appealing. Moreover, these data have been used by other academic researchers such as Atukeren and Seçkin (2009) and Çevik et al. (2013). All indices are transformed to their natural logarithms. 


\section{Empirical Methodology}

This section presents the empirical methods which were estimated for testing the art market efficiency.

Variance ratio tests are designed to test for type-1 random walk (RW1), which assumes homoscedastic increments as well as type-3 random walk (RW3) if the increments are assume to be subject to heteroskedasticity (Campbell et al. 1997). The paper employs the different variance ratio tests, namely the Lo and Mackinlay (1988) test, Wright (2000) non-parametric tests, Chow and Denning (1993) and the Belaire-Franch and Contreras (2004) joint tests.

\section{Lo and MacKinlay (1988) test}

Lo and MacKinlay (1988) proposed a single variance ratio test which uses the fact that if the price of a series (e.g. (art index) at time, $y_{t}$, follows a random walk or martingale, then the increments are said to be serially uncorrelated and the variance of those increments should increase linearly in the sampling intervals. Under the null of a random walk the variance ratio should have a value close to 1 because the variance of the increments of a random walk is linear in the sampling interval.

$y_{t}=y_{t-1}+\mu+\varepsilon_{t}, \varepsilon_{t} \sim \mathrm{IID} \mathrm{N}\left(0, \sigma^{2}\right)$.

If the art index price is mean-reverting, its return is predictable ex ante in the form of a systematic pattern in its dependence on past prices and hence the market is not weak-form efficient. On the other hand, if the art index price follows a random work or martingale, the return is unpredictable from past price information and hence the market is efficient. For sample size $t=1, \ldots T$, the variance ratio begins with the formulation (Wright 2000; Hoque et al., 2007; Charles and Darné, 2009; Mobarek and Fiorante, 2014):

$V R(y ; q)=\left\{\frac{1}{T q} \sum_{t=q}^{T}\left(y_{t}+y_{t-1}+\ldots+y_{t-q+1}-q \hat{\mu}\right)^{2}\right\} \div\left\{\frac{1}{T} \sum_{t=1}^{T}\left(y_{t}-\hat{\mu}\right)^{2}\right\}$,

where $q$ is any positive integer. $\hat{\mu}=T^{-1} \sum_{t-1}^{T} y_{t}$. This is an estimator for the unknown population VR, denoted as $V(q)$, which is the ratio of $1 / q$ times the variance of the $q$-period return to the variance of the one-period return. Lo and Mackinlay (1988) single variance ratio tests the null hypothesis that 
$\mathrm{H}_{0}: V(q)=1$. They provided the test statistic under homoscedastic $\left(\mathrm{M}_{1}\right)$ and heteroscedastic $\left(\mathrm{M}_{2}\right)$ assumptions and these follow asymptotic standard normal distribution. ${ }^{2}$

The $M_{2}$ test is applicable to $y_{t}{ }^{\prime} s$ generated from a martingale difference time series. The usual decision rule for standard normal distribution applies to $M_{1}$ and $M_{2}$.

\section{Wright's (2000) rank-based and sign-based VR tests}

The standard VR tests such as the Lo and Mackinlay (1988) tests are asymptotic tests whose sampling distribution are approximated based on their limiting distributions. The problem with this is that they are biased (severe size distortions and low power) and right-skewed in finite samples, resulting in misleading statistical inference (Lo and Mackinlay, 1989). This is especially true when the sample size is not large enough to justify the asymptotic approximations. Based on this, Wright (2000) proposed the ranks and signs based tests which are non-parametric alternatives to the standard asymptotic VR tests. Wright's (2000) tests have two main advantage over other single and multiple variance ratio tests: first, it is very likely to calculate exact sampling distribution, hence there is no need to resort to asymptotic approximation, and second, it may be more powerful than the conventional tests when the distribution is highly non-normal (Wright, 2000). The tests based on ranks are exact under the i.i.d assumption, whereas the tests based on signs are exact even under conditional heteroskedasticity. Moreover, the rank-based tests display low size distortion under conditional heteroskedasticity (Wright, 2000).

Given $T$ observations of first differences (returns) of a variable, $\left\{y_{1}, \ldots, y_{T}\right\}$ and let $r\left(y_{t}\right)$ be the rank of $y_{t}$ among $y_{1}, y_{2}, \ldots, y_{T}$. Under the null hypothesis that $y_{t}$ is generated from an i.i.d. sequence, $r\left(y_{t}\right)$ is a random permutation of the numbers $1, \ldots, T$ with equal probability. Wright (2000) suggests two rank-based test statistics $R_{1}$ and $R_{2}$ defined as:

$R_{1}(q)=\left(\frac{(T q)^{-1} \sum_{t=q}^{T}\left(r_{1 t}+r_{1 t-1}+\ldots+r_{1 t-q+1}\right)^{2}}{T^{-1} \sum_{t=1}^{T} r_{1 t}^{2}}-1\right)\left(\frac{2(2 q-1)(q-1)}{3 q T}\right)^{-1 / 2}$,

\footnotetext{
${ }^{2}$ Details of these statistics can be found in Lo and Mackinlay (1988).
} 
and

$$
R_{2}(q)=\left(\frac{(T q)^{-1} \sum_{t=q}^{T}\left(r_{2 t}+r_{2 t-1}+\ldots+r_{2 t-q+1}\right)^{2}}{T^{-1} \sum_{t=1}^{T} r_{2 t}^{2}}-1\right)\left(\frac{2(2 q-1)(q-1)}{3 q T}\right)^{-1 / 2}
$$

The $R_{1}$ and $R_{2}$ test statistics share the same exact sampling distribution and their critical values can be obtained by simulating their exact distributions.

Similarly Wright (2000) suggests two tests statistics $S_{1}$ and $S_{2}$ based on the signs of first differences (returns). The tests are based on the null hypothesis that $y_{t}$ is a martingale difference sequence whose unconditional mean is zero and that $s_{t}$ is an i.i.d sequence. The test $S_{2}$ tests for a random walk with a drift. However, it should be noted that Wright's (2000) $S_{2}$ test is not considered here, as his Monte Carlo simulations clearly show that its size and power properties are quite inferior to those of $S_{1}$.

\section{Multiple variance ratio tests}

Lo and MacKinlay (1988) and Wright (2000) tests are both single variance ratio tests. The single variance ratio may not be completely adequate for testing the random walk hypothesis, as it is useful for testing only the individual variance ratios for a specific interval $q$. It is noted that testing with different $q$ values would lead to over rejection of the null hypothesis. Chow and Denning (1993) noted that this sequential procedure leads to size distortion. To overcome this problem Chow and Denning (1993) provide a multiple VR test where the variance ratio of all observation intervals, $q^{\prime} s$ need to be simultaneously equal to 1 . The joint null hypothesis is $\mathrm{H}_{0}: V\left(q_{i}\right)=1$ for $i=1, \ldots, m$ against the alternative that $\mathrm{H}_{1}: V\left(q_{i}\right) \neq 1$ for some holding period $q_{i}$. They provided the joint test statistic for both homoscedastic (MV1) and Heteroskedastic (MV2) assumptions associated with the Lo ad Mackinlay (1988) test. 
Belaire-Franch and Contreras (2004) also proposed multiple rank and sign VR tests by substituting Wright's (2000) rank and sign-based tests in the definition of the Chow and Denning (1993) multiple test procedure. Hence their multiple tests consists of $\mathrm{CD}\left(\mathrm{R}_{1}\right), \mathrm{CD}\left(\mathrm{R}_{2}\right), \mathrm{CD}\left(\mathrm{S}_{1}\right)$ and $\mathrm{CD}\left(\mathrm{S}_{2}\right)$ statistics. $^{3}$ Similarly to Wright's (2000) individual tests, the ranks-based multiple VR tests are sensitive to deviations from the stronger i.i.d. assumptions. However, signs-based multiple VR tests are robust to conditional heteroskedasticity, although $C D_{\left(S_{1}\right)}$ is constructed under the additional assumption of zero drift value. ${ }^{4}$

\section{Kim (2006) wild bootstrap test}

Kim (2006) uses the wild bootstrap which is a resampling method that approximates the sampling distribution of the VR test statistic, and is applicable to data with unknown forms of conditional and unconditional heteroskedasticity (Mammen, 1993; Davidson and Flachaire, 2008; Mackinnon, 2002). The wild bootstrap could be applied to both the Lo and Mackinlay (1988) single variance tests and Chow and Denning (1993) multiple variance tests. We use the wild bootstrap instead of the asymptotic normal probabilities to evaluate the statistical significance of Lo and Mackinlay (1988) tests and its associated Chow-Denning joint tests. This is particularly important given the limited sample size we use for analysis as bootstrapping will help to produce unbiased p-values. Usually a specific form of bootstrap error distribution is required to implement the wild bootstrap test. Kim (2006) recommends using the standard normal distribution since other choices such as the twopoint distribution of Mammen (1993), and the Rademacher distribution discussed in Davidson and Flachaire (2008) produced qualitatively similar sample results. The unit root tests and the approaches presented above test the efficiency market hypothesis by using the random walk model. This is a very special case of the I(1) behaviour and, as earlier mentioned, fractional integration allows for a greater flexibility in the specification of the model.

\section{Empirical Results \\ Preliminary Analysis}

\footnotetext{
${ }^{3}$ Interested readers may get details of the specifications of these test statistics from Chow and Denning (1993) and Belaire-Franch and Contreras (2004)

${ }^{4}$ Belaire-Franch and Contreras (2004) show that the rank-based tests are more powerful than the sign-based tests.
} 
Figure 1: Art indices
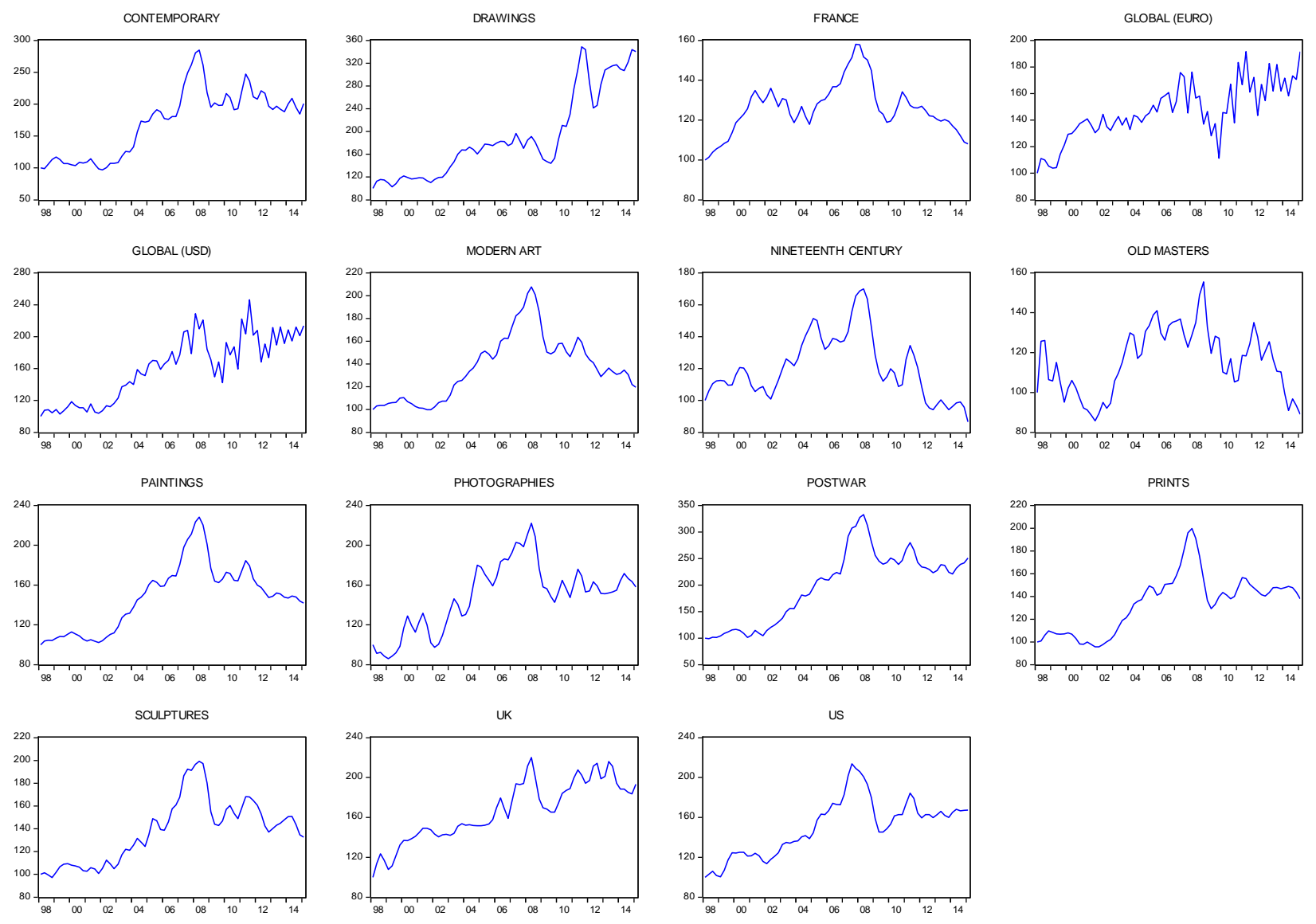
The variables are plotted and presented in Figure 1. It can be observed that the majority of the art indices show some level of volatility while some show an upward trend. Overall, the series do not appear to exhibit clear random walk behavior. However, this will be investigated through formal tests in the next section.

We also present in Table 1 the descriptive statistics for art returns. With the exception of Old Masters and Nineteenth century, the rest of the returns have positive mean. The volatility of the series, as evidenced by the standard deviations, are relatively high with the Global index (USD) exhibiting the highest volatility while France exhibit the lowest. The majority of the indices are negatively skewed with most having kurtosis of approximately 4 which is slightly above the normal kurtosis of 3. The formal test of normality, the Jarque-Bera test, rejects the null of normality for four of the series namely Paintings and Prints at 5\% level and Modern art and US return at 10\% level. With respect to the LM test, the null of no ARCH effect is rejected for all series showing there is strong evidence of conditional heteroskedasticity in all the art return series.

To examine whether there exist commonality and spillover effects among the art indices used for analysis, we present the correlation coefficients in the appendix (see Table A1). We observe that there is a positive correlation between all the art indices. The only exceptions are a negative correlation between Drawings and France (-0.05) and between Drawings and the Nineteenth century (-0.22) indices. The highest positive correlation (0.99) is between Paintings and Modern art while the lowest positive correlation (0.07) is between Drawings and France. Overall, one may conclude that in case of a shock in the art market, there may be some sort of spillover effects between one art price and the other given the generally observed high positive correlation. ${ }^{5}$

\footnotetext{
${ }^{5}$ Although, our paper is not on volatility spillover effects, for such, a formal approach such as Value-at-Risk (VaR) as in Adams et al. (2014) could be used. Adams et al. (2014) examine the spillover effects among four financial institutions using daily data for the time period 04/02/2003 to 12/31/2010 (2,023 observations). However, given the data limitation in this study, quarterly data from 1998:1 to 2015:1 (69 observations), VaR is not possible because of the lack of significant ARCH effects when estimating conditional volatility. Instead we run an OLS regression of each absolute squared returns (volatility) on the rest art volatility series. Our results show that each art volatility has two or more other volatility series exhibiting a significant effect on it as indicated by large t-values. For instance, there is a volatility spillover effect from France, Photographies and Prints to Contemporary and from Nineteenth Century and Prints to Drawings. Similarly, there is a volatility spillover effect from Contemporary, Sculpture, Paintings and UK to France, and from Paintings, Postwar and US to Modern Art. Moreover, given the significant F-statistic in each model which shows the
} 
Table 1: Descriptive statistics of the art return series

\begin{tabular}{|c|c|c|c|c|c|c|c|c|c|}
\hline Series & Mean & Median & Max & Min & $\begin{array}{l}\text { Std. } \\
\text { Dev. }\end{array}$ & Skewness & Kurtosis & $\begin{array}{l}\text { Jarque- } \\
\text { Bera }\end{array}$ & $\mathrm{LM}$ \\
\hline Contemporary & 1.026 & 0.516 & 16.079 & -18.110 & 6.585 & -0.158 & 3.192 & 0.388 & $3.614^{*}$ \\
\hline Drawings & 1.800 & 1.251 & 19.542 & -18.722 & 6.978 & -0.130 & 3.851 & 2.242 & $7.360^{\dagger}$ \\
\hline France & 0.115 & 0.523 & 4.964 & -9.863 & 3.005 & -0.545 & 3.264 & 3.558 & $3.139^{*}$ \\
\hline Global index (Euro) & 0.956 & 1.356 & 28.387 & -21.084 & 10.265 & 0.108 & 3.218 & 0.268 & $8.6566^{\dagger}$ \\
\hline Global index (USD) & 1.117 & 2.064 & 33.216 & -21.120 & 10.981 & 0.424 & 3.568 & 2.947 & $2.983^{*}$ \\
\hline Modern art & 0.262 & 0.552 & 7.666 & -12.664 & 3.949 & -0.614 & 3.659 & $5.508^{*}$ & $10.798 \dagger$ \\
\hline Nineteenth century & -0.213 & 0.425 & 13.603 & -12.864 & 5.247 & -0.297 & 2.950 & 1.006 & $6.898^{\dagger}$ \\
\hline Old Masters & -0.170 & 0.417 & 22.873 & -16.987 & 7.269 & 0.034 & 3.397 & 0.460 & $16.309 \dagger$ \\
\hline Paintings & 0.514 & 0.851 & 9.309 & -12.992 & 3.902 & -0.678 & 4.387 & $10.653^{\dagger}$ & $15.774 \dagger$ \\
\hline Photographies & 0.673 & 0.592 & 17.142 & -16.871 & 7.008 & -0.112 & 2.735 & 0.342 & $3.662^{*}$ \\
\hline Postwar & 1.352 & 1.769 & 16.143 & -10.650 & 5.082 & -0.014 & 3.254 & 0.185 & $8.861^{\dagger}$ \\
\hline Prints & 0.473 & 0.643 & 7.977 & -12.654 & 4.061 & -0.876 & 4.579 & $15.763 \dagger$ & $28.706 \dagger$ \\
\hline Sculptures & 0.415 & -0.023 & 10.625 & -15.138 & 4.655 & -0.350 & 3.734 & 2.915 & $8.824 \dagger$ \\
\hline UK & 0.968 & 0.684 & 12.663 & -11.623 & 4.917 & -0.094 & 3.070 & 0.114 & $8.880^{\dagger}$ \\
\hline US & 0.758 & 0.501 & 9.993 & -12.539 & 4.142 & -0.451 & 3.951 & $4.866^{*}$ & $14.863^{\dagger}$ \\
\hline
\end{tabular}

$\dagger$ and ${ }^{*}$ indicate significance at 5\% and 10\% level respectively. 


\section{Variance Ratio Tests Results}

We investigate the weak-form efficient market hypothesis by testing the random walk or martingale difference hypothesis using variance ratio tests. This paper employs the standard variance ratio test of Lo and MacKinlay, (1988, 1989), the non-parametric-based variance ratio test of Wright (2000) and the joint or multiple-variance ratio test of Chow and Denning (1993) and its modified version by Belaire-Franch and Contreras (2004). The holding periods $\left(q_{i}{ }^{\prime} s\right)$ considered are 2, 4, 8 and 16 months. This is consistent with Deo and Richardson (2003) who advocated for relatively short holding periods when testing for mean-reversion using the variance ratio tests. Table 2 presents the z-statistic for the variance ratios for the individual tests. For the Lo and MacKinlay $(1988,1989)$ tests, we report the results based on both homoscedasticity (M1) and heteroskedasticity (M2) assumptions. The statistical significance of the tests are based on Kim's (2006) wild bootstrap probabilities to guard against small sample bias. The bootstrap p-values for both Lo and Mackinlay (1998) and Wright (2000) tests are computed using 10000 replications. $^{6}$

Starting with the Contemporary art returns, we observe that the null hypothesis is rejected at $1 \%$ for period 2 under the Lo and Mackinlay's (1988) homoscedasticity version of the test. At longer holding periods (4, 8 and 16) however, the null could not be rejected. Similar result is observed under the heteroskedastic assumption with the exception that here the null is rejected at $10 \%$ for period 4. Wright's (2000) tests produce similar results for Contemporary with the null being rejected for period 2 in the rank and rank-score test while it was not rejected under the sign-based test. The null is rejected mainly at periods 2 and 4 for Drawings, Nineteenth century, Photographies and Sculptures. For France and Prints the null is rejected essentially at all periods except at period 16. The null is rejected for Global index (USD) for periods 8 in all cases and 16 in addition for M2 and

joint significance of all the variables in each model, we conclude that there is a spillover effect in the art market. These results are available from authors upon request.

${ }^{6}$ To conserve space, the $p$-values are not presented here. 
Table 2: Individual variance ratio tests of return series

\begin{tabular}{|c|c|c|c|c|c|c|c|c|c|c|c|}
\hline Test & $q$ & Contemporary & Drawings & $\begin{array}{l}\text { France } \\
\text { (Euro) }\end{array}$ & $\begin{array}{l}\text { Global } \\
\text { index } \\
\text { (Euro) }\end{array}$ & $\begin{array}{l}\text { Global } \\
\text { index } \\
\text { (USD) }\end{array}$ & $\begin{array}{l}\text { Modern } \\
\text { art }\end{array}$ & $\begin{array}{l}\text { Nineteenth } \\
\text { century }\end{array}$ & $\begin{array}{l}\text { Old } \\
\text { Masters } \\
\end{array}$ & Paintings & $\begin{array}{l}\text { Photo- } \\
\text { graphies }\end{array}$ \\
\hline & 2 & $3.327^{\dagger}$ & $3.753^{\dagger}$ & $3.820^{\dagger}$ & $-5.460^{\dagger}$ & $-4.833^{\dagger}$ & $4.603^{\dagger}$ & $4.489 \dagger$ & 0.177 & $5.169 \dagger$ & $3.448^{\dagger}$ \\
\hline & 4 & 1.629 & $1.961^{* *}$ & $3.187 t$ & $-3.356+$ & $-2.926 \dagger$ & $3.459 \dagger$ & $2.905^{\dagger}$ & -1.272 & $4.7366^{\dagger}$ & 1.027 \\
\hline & 8 & 0.677 & 0.386 & $2.612^{\dagger}$ & $-2.252^{* *}$ & $-2.095^{* *}$ & $2.795^{\dagger}$ & 0.942 & -0.846 & $3.567 t$ & -0.357 \\
\hline \multirow[t]{4}{*}{ M1 } & 16 & -0.054 & -0.834 & 0.309 & $-1.706^{* *}$ & $-1.616^{* *}$ & $2.097 \dagger$ & -0.038 & -1.029 & $2.244 t^{\dagger}$ & -0.575 \\
\hline & 2 & $2.837 \dagger$ & $2.942 \dagger$ & $3.170 \dagger$ & $-4.086 \dagger$ & $-3.938+$ & $3.327 t$ & $3.550 \dagger$ & 0.263 & $3.413 \dagger$ & $3.147 t$ \\
\hline & 4 & $1.687^{*}$ & $1.930^{* *}$ & $2.838^{\dagger}$ & $-2.536 \dagger$ & $-2.319^{* *}$ & $2.835^{\dagger}$ & $2.496^{\dagger}$ & -1.326 & $3.595^{\dagger}$ & 1.356 \\
\hline & 8 & 1.005 & 1.076 & $2.444^{\dagger}$ & $-1.650^{*}$ & $-1.517^{*}$ & $2.553^{\dagger}$ & 0.893 & -0.855 & $3.146^{\dagger}$ & 0.238 \\
\hline \multirow[t]{4}{*}{ M2 } & 16 & 0.681 & 0.567 & 0.292 & -1.275 & -1.072 & $2.164^{* *}$ & -0.022 & -1.133 & $2.467^{* *}$ & 0.155 \\
\hline & 2 & $2.787^{\dagger}$ & $3.249 \dagger$ & $3.626 \dagger$ & $-5.462 \dagger$ & $0.391 \dagger$ & $3.969^{\dagger}$ & $4.401 \dagger$ & 0.637 & $4.724^{\dagger}$ & $3.076^{\dagger}$ \\
\hline & 4 & 1.206 & 1.567 & $2.722^{\dagger}$ & $-3.456^{\dagger}$ & $0.326^{\dagger}$ & $2.702^{\dagger}$ & $2.549 \dagger$ & -0.799 & $4.309 \dagger$ & 0.618 \\
\hline & 8 & 0.604 & 0.393 & $2.451 \dagger$ & $-2.300 \dagger$ & $0.324^{* *}$ & $2.527^{\dagger}$ & 0.853 & -0.570 & $3.703^{\dagger}$ & -0.561 \\
\hline \multirow[t]{4}{*}{$\mathrm{R} 1$} & 16 & 0.015 & -0.540 & 0.334 & $-1.706^{\dagger}$ & 0.279 & $2.099 \dagger$ & 0.010 & -0.929 & $2.442^{\dagger}$ & -0.573 \\
\hline & 2 & $3.232^{\dagger}$ & $3.618^{\dagger}$ & $3.423{ }^{\dagger}$ & $-5.552 \dagger$ & $-5.022^{\dagger}$ & $4.093^{\dagger}$ & $4.539 \dagger$ & 0.332 & $4.918^{\dagger}$ & $3.466^{\dagger}$ \\
\hline & 4 & 1.579 & $1.946^{* *}$ & $2.556^{\dagger}$ & $-3.492 \dagger$ & $-2.971 \dagger$ & $2.849 \dagger$ & $2.938^{\dagger}$ & -1.129 & $4.461^{\dagger}$ & 1.204 \\
\hline & 8 & 0.801 & 0.555 & $2.157 t$ & $-2.323^{\dagger}$ & $-1.885^{* *}$ & $2.581^{\dagger}$ & 0.932 & -0.799 & $3.613^{\dagger}$ & -0.122 \\
\hline \multirow[t]{4}{*}{$\mathrm{R} 2$} & 16 & 0.069 & -0.558 & 0.008 & $-1.696^{\dagger}$ & -1.351 & $2.065^{\dagger}$ & -0.126 & -1.037 & $2.227 \dagger$ & -0.283 \\
\hline & 2 & 0.970 & $1.940^{\dagger}$ & $3.881^{\dagger}$ & $-3.153 \dagger$ & $-3.153 \dagger$ & $3.395^{\dagger}$ & $2.910^{\dagger}$ & 1.455 & $2.910^{\dagger}$ & $2.183^{* *}$ \\
\hline & 4 & -0.130 & -0.130 & $4.149 \dagger$ & $-1.880^{* *}$ & $-2.009^{* *}$ & $2.658^{\dagger}$ & 0.324 & 0.389 & $2.528^{\dagger}$ & -0.130 \\
\hline & 8 & -0.225 & -0.287 & $3.833{ }^{\dagger}$ & -0.881 & -1.271 & $2.132^{\dagger}$ & -0.553 & 0.266 & $2.849 \dagger$ & -1.066 \\
\hline $\mathrm{S} 1$ & 16 & -0.179 & -0.413 & 1.398 & -0.895 & -1.316 & $1.357^{* *}$ & -0.882 & -0.069 & $2.803^{\dagger}$ & -0.999 \\
\hline
\end{tabular}

Note: $\dagger,{ }^{* *}$ and ${ }^{*}$ represent rejection of the null hypothesis of random walk or martingale at $1 \%, 5 \%$ and $10 \%$ respectively. M1 relates to the Lo and Mackinlay (1988) homoskedasticity (i.e no bias correction) VR test while M2 relates to the case of heteroskedaticity. R1 is the Wright (2000) rank test, R2 is the rank score test and S1 is the sign-based test. q is the holding period in months. For M1, the null hypothesis is: series is a random walk, For M2: series is a Martingale, For R1: series is a random walk, For R2: series is a random walk and For S1 series is a martingale. 
Table 3: Joint or multiple variance ratio tests on return series

\begin{tabular}{|c|c|c|c|c|c|}
\hline Series & $\mathrm{CD}(\mathrm{M} 1)$ & $\mathrm{CD}(\mathrm{M} 2)$ & $\mathrm{CD}(\mathrm{R} 1)$ & $\mathrm{CD}(\mathrm{R} 2)$ & $\mathrm{CD}(\mathrm{S} 1)$ \\
\hline Contemporary & $3.327+(0.003)$ & $2.837 * *(0.012)$ & $2.787+(0.008)$ & $3.232+(0.001)$ & $0.970(0.655)$ \\
\hline Drawings & $3.753+(0.003)$ & $2.941+(0.014)$ & $3.249+(0.003)$ & $3.618+(0.001)$ & $1.940^{*}(0.067)$ \\
\hline France (Euro) & $3.820+(0.001)$ & $3.170+(0.009)$ & $3.626+(0.001)$ & $3.423+(0.002)$ & $4.149+(0.000)$ \\
\hline Global index (Euro) & $5.460+(0.000)$ & $4.086+(0.000)$ & $5.462+(0.000)$ & $5.552+(0.000)$ & $3.153+(0.003)$ \\
\hline Global index (USD) & $4.833 \dagger(0.000)$ & $3.938+(0.003)$ & $5.022+(0.000)$ & $4.892+(0.000)$ & $3.153+(0.003)$ \\
\hline Modern art & $4.603+(0.000)$ & $3.327+(0.009)$ & $3.969+(0.000)$ & $4.093+(0.000)$ & $3.395+(0.001)$ \\
\hline Nineteenth century & $4.489+(0.000)$ & $3.550 \dagger(0.005)$ & $4.401+(0.000)$ & $4.539+(0.000)$ & $2.910+(0.005)$ \\
\hline Old Masters & $1.272(0.530)$ & $1.326(0.576)$ & $0.929(0.728)$ & $1.129(0.583)$ & $1.455(0.286)$ \\
\hline Paintings & $5.169+(0.000)$ & $3.595+(0.006)$ & $4.724+(0.000)$ & $4.918+(0.000)$ & $2.910+(0.007)$ \\
\hline Photographies & $3.448+(0.004)$ & $2.998+(0.010)$ & $3.076+(0.004)$ & $3.466+(0.000)$ & $2.183^{* *}(0.045)$ \\
\hline Post war & $3.913+(0.000)$ & $3.249+(0.007)$ & $3.493+(0.001)$ & $3.780+(0.000)$ & $2.425^{* *}(0.025)$ \\
\hline Prints & $5.620+(0.000)$ & $3.316^{\dagger}(0.009)$ & $4.889+(0.000)$ & $5.153+(0.000)$ & $3.881 \dagger(0.001)$ \\
\hline Sculptures & $3.954+(0.001)$ & $3.062 \dagger(0.009)$ & $3.470+(0.001)$ & $3.709+(0.001)$ & $2.425^{* *}(0.021)$ \\
\hline UK (in GBP) & $2.490 *(0.071)$ & $2.065(0.113)$ & $2.641+(0.014)$ & $2.616+(0.013)$ & $2.183^{* *}(0.037)$ \\
\hline US (USD) & $4.437+(0.001)$ & $3.219+(0.007)$ & $3.376+(0.002)$ & $3.932+(0.000)$ & $1.698(0.139)$ \\
\hline
\end{tabular}

Note: ${ }^{\dagger}, * *$ and ${ }^{*}$ represent rejection of the null hypothesis of random walk or martingale at $1 \%, 5 \%$ and $10 \%$ respectively. Bootstrapped p-values are in parenthesis. CD(M1) is the Chow and Denning (1993) joint test associated with Lo and Mackinlay (1988) homoskedasticicity version of the VR test, CD(M2) is associated with Lo and Mackinlay (1988) heteroskedasticicity version, $\mathrm{CD}(\mathrm{R} 1)$ is associated with Wright (2000) rank test, $\mathrm{CD}(\mathrm{R} 2)$ is associated with the rank-score test while $\mathrm{CD}(\mathrm{S} 1)$ is associated with the sign-based test. For $\mathrm{CD}(\mathrm{M} 1)$, the null hypothesis is: series is a random walk, For $\mathrm{CD}(\mathrm{M} 2)$ : series is a Martingale, For $\mathrm{CD}(\mathrm{R} 1)$ : series is a random walk, For $\mathrm{CD}(\mathrm{R} 2)$ : series is a random walk and For $\mathrm{CD}(\mathrm{S} 1)$ series is a martingale. 
S1 tests. For UK, rejections are observed for only period 2 across all tests while the null cannot be rejected at any level and under any of the tests for Old Masters. US had no rejections at period 16 for Lo and Mackinlay (tests) and at basically periods 8 and 16 for Wright (2000) tests. Overall, at period 2, all individual tests consistently reject the null hypothesis for all returns except the Old Masters. Beyond period 2, results are mixed.

Turning to the joint tests as presented in Table 3, we observe that except for Contemporary, Old Masters, UK and US, all the tests reject the null of random walk or martingale for all the art returns. Whereas the null for UK is rejected by $\mathrm{CD}(\mathrm{M} 2)$, the null for Contemporary and US are rejected by $\mathrm{CD}(\mathrm{S} 1)$ joint tests. However, there is overwhelming evidence of weak-form efficiency for Old Masters consistent with the results from the individual tests. Thus, we can strongly conclude that Old Masters is not predictable. The conclusion is not as strong for Contemporary, UK and US art returns and essentially non-existent for the rest of the returns meaning that these other markets can be predicted based on past prices and hence are not efficient. Results from our variance ratio tests are consistent with those of David et al. (2013). Using a different art index but same methodology, David et al. (2013) rejected the weak form efficiency of the art market.

\section{Robustness Check}

As a robustness check, the results from the linear and non-linear fractional integration methods are presented in this sub-section. Tables A2 refers to the estimates of the differencing parameter $\mathrm{d}$ (and their corresponding 95\% confidence intervals) for the art returns, in the linear model for the three standard cases of no regressors, an intercept, and an intercept with a linear trend. ${ }^{7}$ We observe that a linear time trend seems to be required in case of the two global indices (in USD and Euro), while in the remaining cases, no deterministic terms are required. All the estimated values of $\mathrm{d}$ are below 1; however, we observe substantial differences from one case to another. Starting with those with the highest degrees of dependence, we observe that the unit root null hypothesis (i.e., $\mathrm{d}=1$ ) cannot be rejected in the cases of Prints $(\mathrm{d}=0.98)$, Nineteenth century (0.67), Paintings (0.66), US (0.52), Modern art (0.51) and Photographies (0.32).

\footnotetext{
${ }^{7}$ Note that in some cases the estimates were based on the first differenced data, adding then the value 1 to get the proper order of integration of the series.
} 
Another group of variables are those where the estimated value of $\mathrm{d}$ is significantly different from 0 and 1. Here, we include the following series: Post war (0.40), Sculptures (0.39), Drawings (0.37), France (0.36), and Contemporary (0.29); There are two series where the $\mathrm{I}(0)$ hypothesis cannot be rejected: Photographies (0.32), UK (0.17) and Old Masters (-0.12); and finally two series displaying anti-persistence (i.e, $\mathrm{d}<0$ ): the two global indices (in USD and Euro). Thus, we observe a large degree of heterogeneity in the results presented.

Nevertheless, the possibility of nonlinear trends is also taken into account. Tables A3 reports the estimates of $\mathrm{d}$ ) along with the non-linear coefficients, $\theta_{\mathrm{i}}$ (for $\mathrm{m}=1$ to 4 ) and their corresponding $\mathrm{t}$ values. Note that $\theta_{3}$ and $\theta_{4}$ refer to the nonlinear Chebyshev coefficients in time. We observe only three return series that display some degree of nonlinearity and they are Old masters and the two global indices. If we look at the degrees of integration, though quantitatively we observe some differences, qualitatively they are very similar to those reported in Table A2. The null of unit root hypothesis (i.e $\mathrm{d}=1$ ) cannot be rejected for Paintings, Prints, Photographies, Drawings, Nineteenth century, Modern art and US. The estimated value of $\mathrm{d}$ for France is significantly different from 0 and 1. The null of $\mathrm{I}(0)$ hypothesis cannot be rejected for the following series: Sculptures, Photographies, Old Masters, Modern art, Post war, Contemporary and UK. The Global indices exhibit again an anti-persistent behavior. It may not be surprising that the global market is not efficient while some of the segments are. This is because the global index is an aggregate of the individual indices and since the results of the latter are heterogeneous, then one may well expect any outcome for the global market depending on the driving power of each segment.

Our results may be compared to that of Çevik et al. (2013) who used the same indices though with a different methodology. Their unit root tests show that Sculptures, Photographies, Old Masters, Contemporary, Paintings and Prints are stationary while Drawings and Nineteenth century are nonstationary and hence are weak-form efficient. These findings contrast with ours. However, we note that the unit root tests have lower power than both the variance ratio tests and tests based on the long memory approach. Our overall findings may be related to Erdös and Ormos (2010) who find that the random walk hypothesis does not hold for the US art market using variance ratio tests. However, after accounting for structural breaks they found that the null of random walk cannot be 
rejected and hence there exists weak form efficiency. Although they accounted for structural breaks by conducting the variance ratio tests on sub-samples, our nonlinear fractional integration approach also takes care of any structural breaks that may arise from institutional changes. Therefore, the finding that US art price and some of the other art price indices are efficient under the fractional integration approach is consistent with the subsample analysis of Erdös and Ormos (2010).

\section{Conclusions}

This paper examines the weak-form efficiency hypothesis for 15 art price indices including the Contemporary, Drawings, France, Global index (Euro), Global index (USD), Modern art, Nineteenth century, Old Masters, Paintings, Photographies, Postwar, Prints, Sculptures, UK and US. We use quarterly data from 1998:1 to 2015:1.

The random walk or martingale hypothesis for returns is tested using both individual and multiple variance ratio tests and holding periods of 2, 4, 8 and 16. Results based on the individual tests shows that the null hypothesis is rejected for all the returns at period 2. However, beyond period 2, the results are inconclusive as the hypothesis is rejected at some periods while it is not at other periods. The joints tests show consistent non-rejection of the null hypothesis for Old Masters while the evidence is somewhat weak for Contemporary, US and UK. For the rest of the returns, the joint tests strongly reject the null hypothesis of random walk or martingale. Based on the joint tests we can conclude that Old Masters, Contemporary, US and UK art markets are efficient and hence cannot be predicted based on past price information; thus making it difficult for investors to make excess returns.

We implement a robustness check using the fractional integration which includes the $\mathrm{I}(0)$ and $\mathrm{I}(1)$ hypotheses as particular cases of interest. Results based on the linear long memory model for the return series shows that the null hypothesis of unit root cannot be rejected in the cases of Prints, Nineteenth Century, Paintings, US in USD, Modern Art and Photographies. The estimated value of $\mathrm{d}$ for Post war, Sculptures, Drawings, France, and Contemporary are significantly different from 0 and 1. Results from the nonlinear counterpart show that the null of unit root hypothesis cannot be rejected for Paintings, Prints, Photographies, Drawings, Nineteenth century, Modern art and US. Here the estimated value of $\mathrm{d}$ for France is significantly different from 0 and 1 . The rest of the series

have short memory and are therefore not efficient. Only the US and perhaps Contemporary are 
seem to be efficient irrespective of the method of analysis. Perhaps these two markets have benefited from increased liquidity, better information, globalization, access to financing options, and increased participation. Our results have some implications for investors. Investors can easily grasp excess returns from the non-efficient art markets. This is because they would have an insider price information which is not known to the public. Hence, they can leverage on this to obtain abnormal profits. This is not so with the efficient markets since future price movements in these are determined entirely by information not contained in the price series. The inefficiency of some art markets may also present opportunity for portfolio diversification to investors who hold alternative but less performing assets as this may help them to reduce their investment risks. 


\section{References}

Adams, Z., Roland, Füss, R., and Gropp, R. (2014). Spillover effects among financial institutions: a * state dependent sensitivity Value-at-Risk approach. Journal of Financial and Quantitative Analysis, 49(3), 575-598.

Arouri, M., Hammoudeh, S., Lahiani, A. and Nguyen, D. (2012). Long memory and structural breaks in modelling the return and volatility dynamics of precious metals. The Quarterly Review of Economics and Finance, 52, 207-218.

Ashenfelter, O. and Graddy, K. (2003). Auctions and the price of art. Journal of Economic Literature, 41(3), 763-787.

Atukeren, E. and Seçkin, A. (2009). An analysis of the price dynamics between the Turkish and the international paintings markets. Applied Financial Economics, 19, 1705-1714.

Baumol, W. J. (1986). Unnatural value: or art investment as floating crap game. American Economic Review 76, 10-14.

Belaire-Franch, J. and Contreras, D. (2004). Ranks and signs-based multiple variance ratio tests. Working paper, Department of Economic Analysis, University of Valencia.

Belaire-Franch, J., McGreal, S., Opong, K.K. and Webb, J.R. (2007) A nonparametric variance-ratio test of the behavior of the U.K. real estate and construction indices. International Real Estate Review, 10(2), 94-112.

Campbell, J.Y., Lo, A.W. and MacKinlay, A.C. (1997). The Econometrics of Financial Markets. Princeton University Press, Princeton, NJ.

Campbell, R. (2008). Art as a financial investment. The Journal of Alternative Investments Spring, 10(4), 64-81.

Campbell, J.Y. and P. Perron (1991): "Pitfalls and opportunities: What macroeconomists should know about unit roots”, NBER Macroeconomic Annual, pp. 1141-201.

Çevik, E.I., Atukeren, E. and Korkmaz, T. (2013) Nonlinearity and nonstationarity in international art market prices: evidence from Markov-switching ADF unit root tests. Empirical Economics, 45(2), 675-695.

Charles, A. and Darné, O. (2009). The efficiency of the crude oil markets: Evidence from variance ratio tests, Energy Policy, 37, 4267-4272.

Chow, K. V. and Denning, K. C. (1993). A simple multiple variance ratio test. Journal of Econometrics, 58(3), 385-401. 
Cochrane, J. H. (1988). How big is the random walk in GNP? The Journal of Political Economy 96, 893-920.

Cuestas, J.C. Gil-Alana, L.A. (2016). Testing for long memory in the presence of non-linear deterministic trends with Chebishev polynomials., Studies in Nonlinear Dynamics and Econometrics, 23, 445-468.

David, G., Oosterlinck, K. and Szafarz, A. (2013). Art market inefficiency, Economics Letters 121, 23-25.

Davidson, R. and Flachaire, E. (2008). The wild bootstrap, tamed at last. Journal of Econometrics, 146(1), 162-169.

DeJong, D., J. Nankervis, N.E. Savin and C.H. Whiteman (1992). Integration versus trend stationarity in time series. Econometrica, 60, 423-433.

Deo, R. S. and Richardson, M. (2003). On the asymptotic power of the variance ratio test. Econometric Theory, 19(2), 231-239.

Dickey, D.A and Fuller, W.A. (1979) Distribution of the Estimators for Autoregressive Time Series with a Unit Root, Journal of the American Statistical Association 74, 427-431.

Diebold, F.X. and A. Inoue (2001) Long memory and regime switching, Journal of Econometrics 105, 1, 131-159.

Diebold FX, Rudebusch GD (1991). On the power of Dickey-Fuller test against fractional alternatives. Economics Letters, 35: 155-160.

Erdös, P. and Ormos, M. (2010). Random walk theory and the weak-form efficiency of the US art auction prices. Journal of Banking \& Finance 34 (5), 1062-1076.

Fama, E.F. (1970). Efficient capital markets: a review of theory and empirical work. Journal of Finance 25 (2), 383-417.

Fama, E.F. and French, K.R. (1988), Permanent and temporary components of stock prices, The Journal of Political Economy, 96(2), 246-273.

Frey, B.S. and Eichenberger, R. (1995). On the rate of return in the art market. Survey and evaluation. European Economic Review 39 (3), 528-537.

Frey, B.S. and Pommerehne, W.W. (1989) Art investment: an empirical inquiry. Southern Economic Journal, 56(2), 396-409.

Gil-Alana, L.A. (2008), Fractional integration and structural breaks at unknown periods of time. Journal of Time Series Analysis, 29, 163-185.

Gil-Alana, L.A. and Moreno, A. (2012). Uncovering the US term premium: An alternative route. Journal of Banking and Finance, 36, 1181-1193. 
Gil-Alana, L. A., Aye, G.C. and Gupta, R. (2015). Trends and cycles in historical gold and silver prices. Journal of International Money and Finance, 58(C), 98-109.

Hassler, U. and Wolters, J. (1994). On the power of unit root tests against fractional alternatives. Economics Letters, 45, 1-5.

Hoque, H.A.A.B., Kim, J.H. and Pyun, C.S. (2007) A comparison of variance ratio tests of random walk: A case of Asian emerging stock markets. International Review of Economics and Finance 16, 488-502.

Kapetanious, G. and Y. Shin, 2011, Testing the Null Hypothesis of Nonstationary Long Memory Against the Alternative Hypothesis of a Nonlinear Ergodic Model, Econometrics Review 30, 6, 620-645.

Kim, J.H. (2006). Wild bootstrapping variance ratio tests. Economics Letters, 92, 38-43.

Korteweg, A.G., Kräussl, R. and Verwijmeren, P. (2016) Does it pay to invest in art? A SelectionCorrected Returns Perspective, forthcoming in Review of Financial Studies 29, 4, 1007-1038.

Kwiatkowski, D., P.C.D Phillips, P. Schmidt and Y. Shin (1992) Testing the null hypothesis of stationarity against the alternative of a unit root: How sure are we that economic time series have a unit root? Journal of Econometrics 54, 159-178.

Lee D, Schmidt P (1996). On the power of the KPSS test of stationarity against fractionally integrated alternatives. Journal of Econometrics, 73: 285-302.

Liu, C.Y., and He, J. (1991). A variance ratio tests of random walks in foreign exchange rates. Journal of Finance 46, 773-785.

Lo, A. W. and MacKinlay, A. C. (1988). Stock market prices do not follow random walks: Evidence from a simple specification test. Review of Financial Studies, 1(1), 41-66.

Lo, A. W. and MacKinlay, A. C. (1989). The size and power of the variance ratio test in finite samples. Journal of Econometrics, 40(2), 203-238.

Louargand, M.A. and McDaniel, J.R. (1991). Price efficiency in the art auction market, Journal of Cultural Economics, 15(2), 53-65.

Mammen, E. (1993) Boostrap and wild bootstrap for high dimensional linear models. The Annals of Statistics, 21, 255-285.

MacKinnon, J.G. (2002) Bootstrap inference in econometrics. Canadian Journal of Economics, 35, 615-645.

Mei, J. and Moses, M. (2002). Art as an investment and the underperformances of masterpieces. The American Economic Review 92, 5, 1656-1668. 
Mobarek, A. and Fiorante, A. (2014). The prospects of BRIC countries: Testing weak-form efficiency. Research in International Business and Finance, 30, 217-232.

Munteanu, A., and Pece, A., (2015) Investigating art market efficiency, Procedia - Social and Behavioral Sciences 188. 82-88.

Nelson, C.R., J. Piger and E. Zivot (2001) Markov regime-switching and unit root tests. Journal of Business Economics and Statistics, 19, 404-415.

Perron, P. (1989) The great crash, the oil price shock, and the unit root hypothesis. Econometrica, 57, 1361-1401.

Pesando, J.E. (1993) Arts as an investment: The market for modern prints. American Economic Review, 83, 1075-1089.

Phillips, P. C. B. and P. Perron (1988) Testing for a unit root in time series regression, 22 Biometrica, 75, 335-346.

Poterba, J.M. and Summers, L.H. (1988) Mean reversion in stock prices: Evidence and Implications, Journal of Financial Economics, 22(1), 27-59.

Renneboog, L. and Spaenjers, C. (2013). Buying beauty: on prices and returns in the art market. Management Science, 59 (1), 36-53.

Summers, L. H. (1986). Does the stock market rationally reflect fundamental values? The Journal of Finance 41, 591-601.

Wright, J. H. (2000). Alternative variance-ratio tests using ranks and signs. Journal of Business \& Economic Statistics, 18(1), 1-9. 


\section{Appendix}

Table A1: Correlation between the art market indices

\begin{tabular}{|c|c|c|c|c|c|c|c|c|c|c|c|c|}
\hline & CONTEMPORARY & DRAW & FRANCE & GLO_EUR & GLO_US & MODERN & NINETEEN & OLD_M & PAINT & РнОТО & POSTWAR & PRINT \\
\hline CONTEMPORARY & 1.00 & & & & & & & & & & & \\
\hline DRAW & 0.63 & 1.00 & & & & & & & & & & \\
\hline FRANCE & 0.50 & -0.05 & 1.00 & & & & & & & & & \\
\hline GLO_EUR & 0.68 & 0.80 & 0.39 & 1.00 & & & & & & & & \\
\hline GLO_US & 0.91 & 0.82 & 0.35 & 0.88 & 1.00 & & & & & & & \\
\hline MODERN & 0.90 & 0.33 & 0.70 & 0.51 & 0.76 & 1.00 & & & & & & \\
\hline NINETEEN & 0.44 & -0.22 & 0.69 & 0.09 & 0.26 & 0.73 & 1.00 & & & & & \\
\hline OLD_M & 0.55 & 0.07 & 0.41 & 0.15 & 0.42 & 0.72 & 0.64 & 1.00 & & & & \\
\hline PAINT & 0.95 & 0.44 & 0.66 & 0.58 & 0.83 & 0.99 & 0.66 & 0.69 & 1.00 & & & \\
\hline Рното & 0.88 & 0.49 & 0.65 & 0.69 & 0.82 & 0.90 & 0.61 & 0.57 & 0.92 & 1.00 & & \\
\hline POSTWAR & 0.98 & 0.63 & 0.54 & 0.70 & 0.91 & 0.92 & 0.44 & 0.55 & 0.96 & 0.90 & 1.00 & \\
\hline PRINT & 0.95 & 0.56 & 0.56 & 0.65 & 0.87 & 0.93 & 0.58 & 0.62 & 0.96 & 0.92 & 0.95 & 1.00 \\
\hline SCULPTURE & 0.95 & 0.51 & 0.65 & 0.64 & 0.86 & 0.96 & 0.57 & 0.63 & 0.98 & 0.90 & 0.96 & 0.96 \\
\hline UK & 0.87 & 0.79 & 0.46 & 0.84 & 0.89 & 0.69 & 0.14 & 0.31 & 0.76 & 0.77 & 0.87 & 0.80 \\
\hline US & 0.93 & 0.60 & 0.66 & 0.77 & 0.88 & 0.90 & 0.51 & 0.53 & 0.93 & 0.94 & 0.95 & 0.95 \\
\hline
\end{tabular}


Table A2: Estimates of $d$ (and 95\% confidence intervals) in the return series

\begin{tabular}{|c|c|c|c|}
\hline Series & No regressors & An intercept & A linear time trend \\
\hline Global index (USD) & $-0.48 \quad(-0.56,-0.35)$ & $-0.51 \quad(-0.62,-0.35)$ & $-0.55(-0.68,-0.38)$ \\
\hline Global Index (Euro) & $-0.70 \quad(-0.78,-0.51)$ & $-0.54 \quad(-0.62,-0.40)$ & $-0.60(-0.71,-0.44)$ \\
\hline Paintings & $0.66(0.35,1.29)$ & $0.67 \quad(0.35,1.32)$ & $0.68 \quad(0.33,1.32)$ \\
\hline Prints & $0.98 \quad(0.51,1.74)$ & $0.98 \quad(0.52,1.76)$ & $0.98 \quad(0.52,1.80)$ \\
\hline Sculptures & $0.39 \quad(0.10,0.99)$ & $0.39 \quad(0.10,0.98)$ & $0.37 \quad(0.06,0.98)$ \\
\hline Photographies & $0.32 \quad(-0.02,1.03)$ & $0.32 \quad(-0.02,1.08)$ & $0.32(-0.09,1.08)$ \\
\hline Drawings & $0.37 \quad(0.03,0.96)$ & $0.40 \quad(0.03,1.16)$ & $0.41 \quad(0.02,1.16)$ \\
\hline Old Masters & $-0.12(-0.29,0.16)$ & $-0.12(-0.29,0.16)$ & $-0.14 \quad(-0.33,0.19)$ \\
\hline Nineteenth century & $0.67 \quad(0.18,1.56)$ & $0.80 \quad(0.18,1.68)$ & $0.83(0.18,1.66)$ \\
\hline Modern art & $0.51 \quad(0.24,1.11)$ & $0.51 \quad(0.24,1.10)$ & $0.50 \quad(0.21,1.11)$ \\
\hline Post war & $0.40 \quad(0.17,0.82)$ & $0.38 \quad(0.16,0.83)$ & $0.38 \quad(0.12,0.83)$ \\
\hline Contemporary & $0.29 \quad(0.03,0.88)$ & $0.29 \quad(0.03,0.87)$ & $0.27 \quad(0.00,0.88)$ \\
\hline US (in USD) & $0.52 \quad(0.21,1.08)$ & $0.51 \quad(0.20,1.08)$ & $0.51 \quad(0.17,1.08)$ \\
\hline UK (in GBP) & $0.17 \quad(-0.22,0.90)$ & $0.15 \quad(-0.17,0.92)$ & $0.13(-0.24,0.92)$ \\
\hline France (in Euro) & $0.36(0.15,0.92)$ & $0.35 \quad(0.15,0.70)$ & $0.30 \quad(0.06,0.69)$ \\
\hline
\end{tabular}

In bold the significant models according to the deterministic terms. In parenthesis the $95 \%$ confidence bands. 
Table A3: Estimates of $d$ and nonlinear coefficients in the return series

\begin{tabular}{|c|c|c|c|c|c|}
\hline Series & $\mathrm{d}$ & $\theta_{1}$ & $\theta_{2}$ & $\theta_{3}$ & $\theta_{4}$ \\
\hline Global index (USD) & $-0.72 \quad(-0.89,-0.49)$ & $\begin{array}{l}1.103 \\
(1.05)\end{array}$ & $\begin{array}{c}0.378 \\
(2.10)\end{array}$ & $\begin{array}{l}-0.254 \\
(-1.09)\end{array}$ & $\begin{array}{l}-0.765 \\
(-2.65)\end{array}$ \\
\hline Global Index (Euro) & $-0.74 \quad(-0.91,-0.60)$ & $\begin{array}{l}0.859 \\
(9.54)\end{array}$ & $\begin{array}{c}0.373 \\
(2.42)\end{array}$ & $\begin{array}{l}0.595 \\
(2.95)\end{array}$ & $\begin{array}{c}0.091 \\
(0.36)\end{array}$ \\
\hline Paintings & $0.64(0.20,1.32)$ & $\begin{array}{l}1.770 \\
(0.43)\end{array}$ & $\begin{array}{l}1.486 \\
(0.64)\end{array}$ & $\begin{array}{l}-0.612 \\
(-0.36)\end{array}$ & $\begin{array}{l}-0.674 \\
(-0.51)\end{array}$ \\
\hline Prints & $0.97 \quad(0.47,1.65)$ & $\begin{array}{l}1.828 \\
(0.14)\end{array}$ & $\begin{array}{l}0.733 \\
(0.10)\end{array}$ & $\begin{array}{l}-0.603 \\
(-0.16)\end{array}$ & $\begin{array}{l}-0.829 \\
(-0.32)\end{array}$ \\
\hline Sculptures & $0.31 \quad(-0.09,0.98)$ & $\begin{array}{l}0.456 \\
(0.27)\end{array}$ & $\begin{array}{l}0.964 \\
(0.82)\end{array}$ & $\begin{array}{l}-0.816 \\
(-0.79)\end{array}$ & $\begin{array}{l}-0.478 \\
(-0.51)\end{array}$ \\
\hline Photographies & $0.26 \quad(-0.23,1.07)$ & $\begin{array}{l}0.348 \\
(0.16)\end{array}$ & $\begin{array}{l}0.714 \\
(0.44)\end{array}$ & $\begin{array}{l}-0.458 \\
(-0.32)\end{array}$ & $\begin{array}{l}-1.223 \\
(-0.92)\end{array}$ \\
\hline Drawings & $0.41 \quad(0.02,1.16)$ & $\begin{array}{l}2.467 \\
(0.66)\end{array}$ & $\begin{array}{l}0.277 \\
(0.11)\end{array}$ & $\begin{array}{l}0.535 \\
(0.27)\end{array}$ & $\begin{array}{l}0.260 \\
(0.15)\end{array}$ \\
\hline Old Masters & $-0.28 \quad(-0.52,0.11)$ & $\begin{array}{l}-0.164 \\
(-0.55)\end{array}$ & $\begin{array}{l}0.827 \\
(2.01)\end{array}$ & $\begin{array}{l}-0.858 \\
(-1.85)\end{array}$ & $\begin{array}{l}-0.527 \\
(-1.04)\end{array}$ \\
\hline Nineteenth century & $0.83(0.10,1.57)$ & $\begin{array}{l}.664 \\
(0.24)\end{array}$ & $\begin{array}{l}2.237 \\
(0.35)\end{array}$ & $\begin{array}{l}-0.346 \\
(-0.09)\end{array}$ & $\begin{array}{l}-0.177 \\
(-0.06)\end{array}$ \\
\hline Modern art & $0.43 \quad(-0.01,1.09)$ & $\begin{array}{l}0.643 \\
(0.31)\end{array}$ & $\begin{array}{l}1.408 \\
(1.09)\end{array}$ & $\begin{array}{l}-0.779 \\
(-0.72)\end{array}$ & $\begin{array}{l}-0.600 \\
(-0.65)\end{array}$ \\
\hline Post war & $0.27 \quad(-0.08,0.76)$ & $\begin{array}{l}1.478 \\
(0.95)\end{array}$ & $\begin{array}{l}0.959 \\
(0.85)\end{array}$ & $\begin{array}{l}-0.729 \\
(-0.72)\end{array}$ & $\begin{array}{l}-1.407 \\
(-1.54)\end{array}$ \\
\hline Contemporary & $0.21 \quad(-0.17,0.87)$ & $\begin{array}{l}1.190 \\
(0.70)\end{array}$ & $\begin{array}{l}0.830 \\
(0.63)\end{array}$ & $\begin{array}{l}-0.873 \\
(-0.73)\end{array}$ & $\begin{array}{l}-1.025 \\
(-0.91)\end{array}$ \\
\hline US (in USD) & $0.49 \quad(0.15,1.07)$ & $\begin{array}{l}1.106 \\
(0.39)\end{array}$ & $\begin{array}{l}0.899 \\
(0.53)\end{array}$ & $\begin{array}{l}0.002 \\
(0.02)\end{array}$ & $\begin{array}{l}-0.491 \\
(-0.43)\end{array}$ \\
\hline UK (in GBP) & $0.12 \quad(-0.27,0.90)$ & $\begin{array}{l}1.053 \\
(1.14)\end{array}$ & $\begin{array}{l}0.818 \\
(1.03)\end{array}$ & $\begin{array}{l}0.231 \\
(0.30)\end{array}$ & $\begin{array}{l}0.532 \\
(0.73)\end{array}$ \\
\hline France (in Euro) & $0.30 \quad(0.06,0.69)$ & $\begin{array}{l}0.112 \\
(0.11)\end{array}$ & $\begin{array}{l}0.940 \\
(1.31)\end{array}$ & $\begin{array}{l}0.034 \\
(0.05)\end{array}$ & $\begin{array}{l}0.236 \\
(0.41)\end{array}$ \\
\hline
\end{tabular}

In bold, the significant coefficients at the $5 \%$ level. 